\title{
Postoperative analgesia for hip arthroplasty: comparison of continuous lumbar plexus block and epidural analgesia
}

\author{
Analgesia pós-operatória da artroplastia do quadril: comparação do bloqueio de plexo lombar \\ contínuo com a analgesia peridural
}

Gabriela Maria Pereira da Silva e Costa1, Inês Martins Carvalho², Ana Isabel Rodrigues Castro ${ }^{3}$, Neusa Cristina Ribeiro Lages ${ }^{4}$, Carlos Manuel Machado Correia ${ }^{4}$

\section{ABSTRACT}

BACKGROUND AND OBJECTIVES: Postoperative pain after total hip arthroplasty is moderate to severe and requires effective analgesic techniques. This study aimed at comparing continuous lumbar plexus block and epidural analgesia in patients submitted to hip arthroplasty.

METHODS: This is a prospective, observational and analytical study of patients submitted to hip arthroplasty in a two-year period, under postoperative analgesia with continuous lumbar plexus block and epidural analgesia. Patients were divided according to the analgesic technique chosen by the anesthesiologist. The protocol consists in continuous perfusion of $0.2 \%$ ropivacaine $(5 \mathrm{~mL} / \mathrm{h})$ via continuous lumbar plexus block catheter or $0.1 \%$ ropivacaine and fentanyl $(3 \mu \mathrm{g} / \mathrm{mL})(5 \mathrm{~mL} / \mathrm{h})$ via epidural catheter. Using Acute Pain Unit records, three postoperative days were compared between continuous lumbar plexus block and epidural analgesia with regard to pain intensity, rescue analgesia, complications and hospital stay.

RESULTS: Participated in the study 162 patients. Most patients of both groups had no pain in the first postoperative day $(77.6 \%$ continuous lumbar plexus block versus $79.2 \%$ epidural). Both groups were not different with regard to pain intensity and need for rescue analgesia $(23.5 \%$ continuous lumbar plexus block versus $22.1 \%$ epidural). Continuous lumbar plexus block group had fewer complications ( $4.7 \%$ versus $23.4 \%$ ), namely motor block, nausea, vomiting and itching. The low number of complications does not allow the detection of significant differences between techniques. Most patients of both groups were discharged in the third postoperative day.

1. Centro Hospitalar do Tâmega e Sousa, Penafiel, Portugal.

2. Centro Hospitalar de Lisboa Ocidental, Departamento de Anestesiologia, Lisboa, Portugal. 3. Faculdade de Ciências da Universidade do Porto, Departamento de Ciências de Computadores, Porto, Portugal.

4. Centro Hospitalar do Alto Ave, Departamento de Anestesiologia, Guimarães, Portugal.

Submitted in October 04, 2015.

Accepted for publication in January 20, 2016.

Conflict of interests: none - Sponsoring sources: none.

Correspondence to:

Gabriela Maria Pereira da Silva e Costa

Avenida Cidade de Guimarães, 64

4480-660 Vila do Conde, Portugal.

E-mail: gabrielacosta85@gmail.com

(C) Sociedade Brasileira para o Estudo da Dor
CONCLUSION: As compared to epidural analgesia, continuous lumbar plexus block has provided similar analgesia with fewer complications.

Keywords: Epidural analgesia, Hip arthroplasty, Lumbar plexus block, Postoperative pain.

\section{RESUMO}

JUSTIFICATICA E OBJETIVOS: A dor pós-operatória da artroplastia total do quadril tem intensidade moderada a intensa, exigindo a realização de técnicas analgésicas eficazes. $\mathrm{O}$ objetivo deste estudo foi comparar o bloqueio do plexo lombar contínuo com a analgesia peridural em pacientes submetidos à artroplastia de quadril.

MÉTODOS: Estudo retrospectivo, observacional e analítico dos pacientes submetidos à artroplastia de quadril durante dois anos, sob analgesia pós-operatória por bloqueios do plexo lombar contínuo e peridural. Os pacientes foram divididos de acordo com a técnica analgésica escolhida pelo anestesiologista. $\mathrm{O}$ protocolo consiste em infusão contínua de ropivacaína a $0,2 \%$ $(5 \mathrm{~mL} / \mathrm{h})$ via cateter de bloqueio do plexo lombar contínuo ou em ropivacaína a $0,1 \%$ e fentanil $3 \mu \mathrm{g} / \mathrm{mL}(5 \mathrm{~mL} / \mathrm{h})$ via cateter peridural. Recorrendo aos registos da Unidade de Dor Aguda, foram comparados os três dias pós-operatórios dos grupos bloqueio do plexo lombar contínuo e peridural em relação à intensidade da dor, analgesia de resgate, complicaçóes e tempo de internação hospitalar.

RESULTADOS: Foram incluídos 162 pacientes. A maioria de ambos os grupos náo apresentou queixas de dor no primeiro dia pós-operatório $(77,6 \%$ bloqueio do plexo lombar contínuo versus $79,2 \%$ peridural). Ambos os grupos não diferiram em relação à intensidade de dor nem à incidência de necessidade de analgesia de resgate $(23,5 \%$ bloqueio do plexo lombar contínuo versus $22,1 \%$ peridural). O grupo bloqueio do plexo lombar contínuo registrou menos complicaçôes (4,7\% versus 23,4\%), nomeadamente bloqueio motor, náuseas, vômitos e prurido. A rara ocorrência de complicaçóes náo permite detectar diferenças significativas entre as técnicas. A maioria dos pacientes de ambos os grupos obteve alta hospitalar no $3^{\circ}$ dia pós-operatório.

CONCLUSÃO: Em relação à analgesia peridural, o bloqueio do plexo lombar contínuo proporcionou analgesia semelhante com menos complicaçôes.

Descritores: Analgesia peridural, Artroplastia de quadril, Bloqueio do plexo lombar, Dor pós-operatória. 


\section{INTRODUCTION}

Due to population aging and the high prevalence of hip osteoarthritis among the elderly, total hip arthroplasty (THA) is an increasingly frequent procedure. Older age and multiple associated comorbidities may be an anesthetic and analgesic challenge. THA postoperative pain (POP) is moderate to severe and worsens with mobilization, being especially severe during the first 24 postoperative hours. Patients' recovery requires effective analgesia to assure comfort and satisfaction necessary for early mobilization and functional rehabilitation. So, adequate THA analgesia speeds recovery and minimizes postoperative morbility-mortality ${ }^{1-3}$.

Different analgesic techniques to provide post-THA pain relief were studied, such as intravenous patient-controlled analgesia (PCA) with opioids, epidural analgesia, peripheral nerves block and lumbar plexus block (LPB). The technique with better analgesic efficacy, safety and postoperative recovery has not yet been determined ${ }^{2}$.

Therapeutic intravenous PCA regimens offer poor pain relief during movement and have secondary opioid effects and several technical problems. Most common postoperative THA analgesia is the epidural block, although presenting known adverse effects, such as hypotension, nausea, vomiting, pruritus, urinary retention, motor block and respiratory depression. Peripheral nerves block provides excellent analgesia with little motor and sympathetic blocks, preventing adverse effects of local anesthetics and opioids administered to the neuraxis ${ }^{3}$. Recently, LPB started to receive more attention as THA analgesic technique ${ }^{1-3}$.

Lumbar plexus is responsible for skin sensitivity in the side of the thigh and originates some branches to the hip ${ }^{4}$. So, posterior LPB is able to promote effective unilateral analgesia, to decrease consumption of other analgesics and to contribute to patients' rehabilitation and satisfaction after THA $^{2}$. Single shot LPB analgesia is limited to the first 8 postoperative hours, but may be prolonged by the introduction of a continuous infusion catheter ${ }^{5}$.

The scarcity of clinical studies comparing the analgesic efficacy and the safety profile of continuous lumbar plexus block (cLPB) versus epidural analgesia in patients submitted to THA has called our attention, so we considered important to investigate whether cLPB may replace epidural analgesia to decrease the incidence of adverse effects and to speed recovery, functional rehabilitation and hospitalization time.

This study aimed at carrying out a prospective analysis of the postoperative period of patients submitted to THA to compare analgesic efficacy, safety and hospitalization time of cLPB and epidural block.

\section{METHODS}

This was a retrospective study carried out in the Centro Hospitalar Alto Ave (Guimarães, Portugal) from January 1, 2011 to December 31, 2012, including all patients submitted to CLPB and epidural block for postoperative THA an- algesia or THA review. Exclusion criteria were the need to change analgesic protocol due to failed block or insufficient analgesia.

Anesthetic and analgesic techniques were chosen by anesthesiologists according to their preference and patients condition. Catheters for cLPB or epidural analgesia were installed before anesthetic induction. Anesthetic technique was balanced general anesthesia (BGA) or spinal block (SB) with $0.5 \%$ isobaric bupivacaine or $0.5 \%$ isobaric levobupivacaine.

Approach and catheter introduction technique for cLPB was that described by Capdevila et al. ${ }^{4}$ with dual guidance (electric stimulation and ultrasound ${ }^{6}$ ). After catheter insertion, $20 \mathrm{~mL}$ of $0.5 \%$ ropivacaine were administered. After surgery, in the postoperative care unit, patients with cLPB started continuous perfusion of $0.2 \%$ ropivacaine $(5 \mathrm{~mL} / \mathrm{h}$, via elastomer).

Epidural catheter was inserted in $\mathrm{L}_{3}-\mathrm{L}_{4}$ or $\mathrm{L}_{4}-\mathrm{L}_{5}$ spaces with cephalic introduction of 3 to $5 \mathrm{~cm}$ of $20 \mathrm{G}$ multibore catheter, followed by the administration of ropivacaine and fentanyl in doses chosen by the anesthesiologist. After surgery, patients with epidural catheter started $0.1 \%$ ropivacaine and $3 \mu \mathrm{g} / \mathrm{mL}$ fentanyl $(5 \mathrm{~mL} / \mathrm{h}$, via elastomer).

Postoperative adjuvant analgesia for both groups was paracetamol $(1000 \mathrm{mg}$ every $6 \mathrm{~h})$ with or without the association of non-steroid anti-inflammatory drugs $(15-30 \mathrm{mg}$ ketorolac or $20-40 \mathrm{mg}$ parecoxib every 12 hours), according to comorbidities of each patient.

The Acute Pain Unit (APU) team has visited patients at least once a day. In both groups, rescue dose $(5 \mathrm{~mL}$ of $0.2 \%$ ropivacaine) was administered whenever patients complained of pain with intensity above 3 at rest or 4 at mobilization. Ropivacaine perfusion was withdrawn in the third postoperative day when pain intensity was below 3 at rest and 4 at mobilization. Catheter was removed up to the fourth postoperative day, unless otherwise determined by the anesthesiologist.

The three postoperative days were evaluated using APU clinical records to collect the following data: gender and age; physical status according to the American Society of Anesthesiology (ASA); anesthetic and analgesic techniques; pain intensity at rest and at movement, according to the numeric pain scale (scale $0-10: 0=$ no pain; $1-2=$ mild pain; $3-7=$ moderate pain; $8-10=$ severe pain); sensory block checked by needle prick (scale $0-2: 0=$ pain at needle prick; $1=$ analgesia/tactile sensitivity at needle prick; 2 = anesthesia/lack of needle prick perception); number of rescue analgesia administrations; complications, namely those catheter-associated, nausea and vomiting, pruritus and motor block according to Bromage score for lower limbs (scale 0-3: $0=$ no motor block; 1 = able to overcome gravity without overcoming resistance; 2 = able to move the limb without overcoming gravity; and 3 = complete motor block) and hospitalization time. Pain intensity, sensory block and number of patients needing rescue analgesia were used to evaluate analgesic efficacy of both techniques. Safety profile is inferred based on the incidence of complications of each technique. 


\section{Statistical analysis}

Program SPSS version 17.0 (SPSS Inc., Chicago, IL, USA) was used to compare patients under epidural analgesia or cLPB. Demographic data were compared between groups, as well as the incidence of pain or complications in the postoperative period ( $t$, Chi-square and Wilcoxon-MannWhitney tests). For all tests, $\mathrm{p}<0.05$ was considered statistically significant.

This study was approved by the Anesthesiology Ethics Committee, Centro Hospitalar Alto Ave, process 23/2012.

\section{RESULTS}

During the study period, a universe of 165 patients was evaluated. Three patients were excluded for not establishing blockade or for insufficient analgesia ( 1 from the epidural group and 2 from the cLPB group). Table 1 shows characterization of sample and of groups. Sample is made up of 162 patients with mean age of $67.22 \pm 11.57$ years [32;91]; $50.6 \%$ were males; $58.6 \%$ ASA II; $70.4 \%$ submitted to THA; $84.0 \%$ under SB. The epidural group has 77 patients with mean age of $65.44 \pm 4.95$ years $[37 ; 84]$; $55.8 \%$ were females; $63.6 \%$ submitted to THA; $85.7 \%$ under SB. The cLPB group has 85 patients with mean age of $68.62 \pm 12.29$ years [32;91]; $56.5 \%$ were males; $72.9 \%$ submitted to THA; $82.4 \%$ under BGA. Groups are similar and do not have significant differences with regard to age ( $t$ test), gender, ASA and type of procedure (Chi-square test).

Most patients of both groups had no pain at rest during the first postoperative day (77.6\% cLPB versus $79.2 \%$ epidural). Approximately $22.4 \%$ of patients $(n=19)$ of the cLPB group had pain complaints, corresponding to mild pain in $15.3 \%$ of cases $(n=13)$. These values are not significantly different from the epidural group, which had pain in $20.8 \%$ of cases $(\mathrm{n}=16)$, classified as mild pain by $14.3 \%$ of patients $(\mathrm{n}=11)$ (Figure 1). With regard to pain at movement during the first POD, $58.8 \%$ of cLPB group $(n=50)$ and $55.8 \%$ of the epidural group $(n=43)$ had no pain and most of remaining patients had mild pain (24.7\% cLPB versus $26.0 \%$ epidural) (Figure 2). In both groups, POP at rest and at movement has decreased along the second and third postoperative days (Figures 1 and 2). Groups were not different with regard to pain at rest and at movement during the three postoperative days. Group cLPB sensory block was significantly better as com-

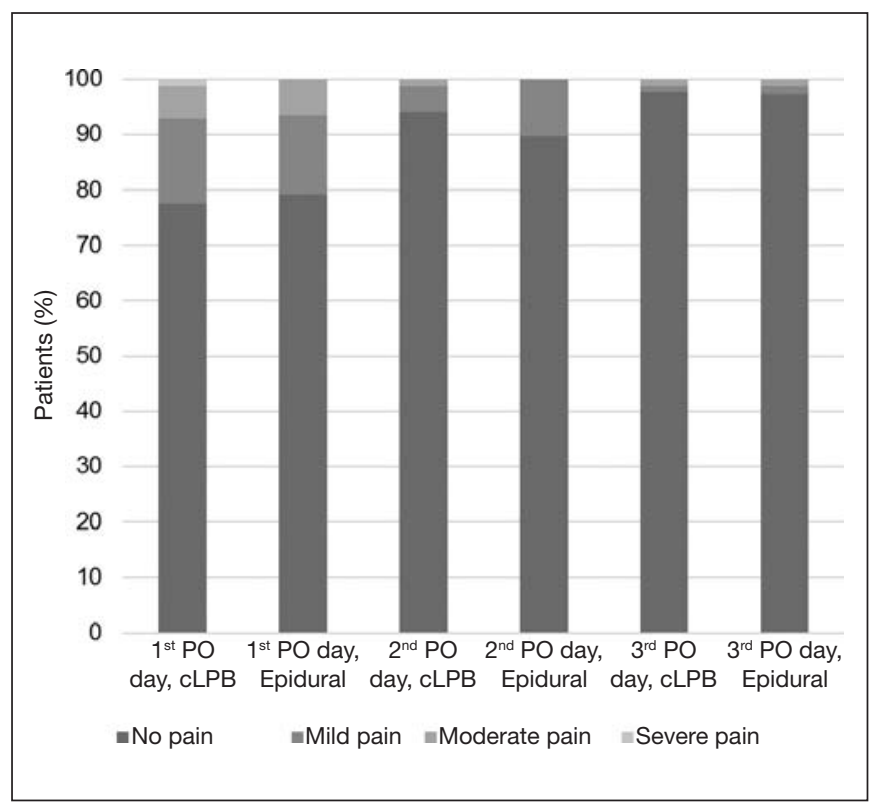

Figure 1. Comparison of pain intensity at rest along the three days for both groups

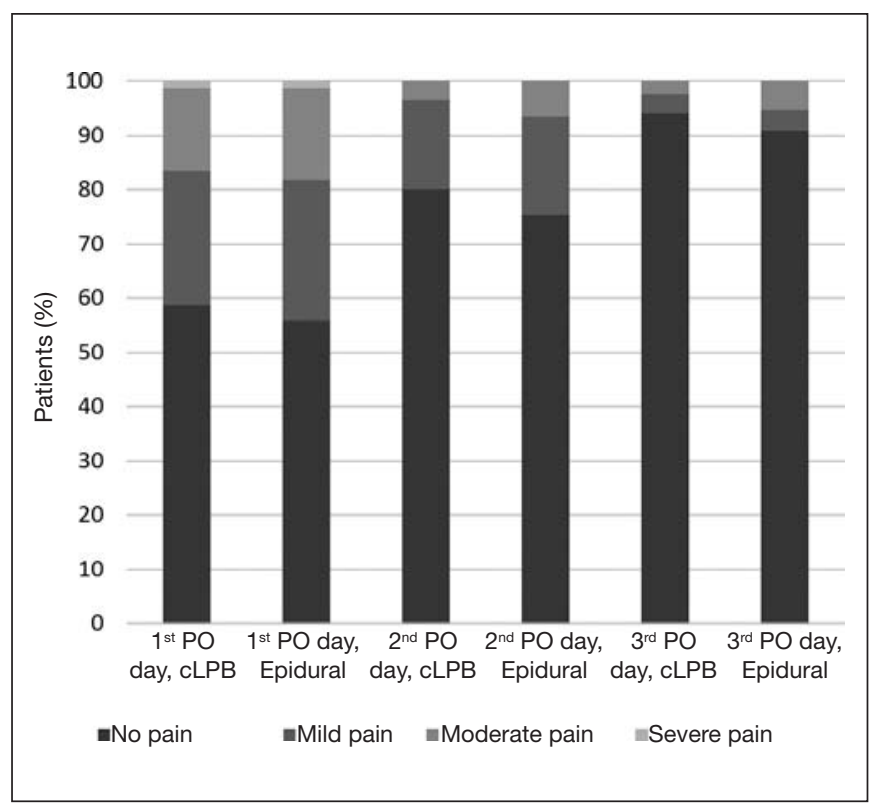

Figure 2. Comparison of pain intensity at movement along the three days for both groups

Table 1. Distribution and characterization of evaluated patients and groups

\begin{tabular}{|c|c|c|c|c|c|c|c|c|c|c|c|}
\hline \multirow[t]{2}{*}{ Groups } & \multirow[t]{2}{*}{ Age } & \multicolumn{2}{|c|}{ Gender } & \multicolumn{4}{|c|}{ ASA } & \multicolumn{2}{|r|}{ Surgery } & \multicolumn{2}{|c|}{ Anesthetic techique } \\
\hline & & Male & Female & I & ॥ & III & $?$ & THA & THA Review & SB & BGA \\
\hline $\begin{array}{l}\text { Epidural } \\
(\mathrm{n}=77)\end{array}$ & $65.44 \pm 4.95$ & 34 & 43 & 5 & 43 & 14 & 15 & 55 & 22 & 66 & 11 \\
\hline $\begin{array}{l}\text { cLPB } \\
(n=85)\end{array}$ & $68.62 \pm 12.29$ & 48 & 37 & 3 & 52 & 17 & 13 & 59 & 26 & 70 & 15 \\
\hline $\begin{array}{l}\text { Total } \\
(n=162)\end{array}$ & $67.22 \pm 11.57$ & 82 & 80 & 8 & 95 & 31 & 28 & 114 & 48 & 136 & 26 \\
\hline
\end{tabular}


pared to the epidural group. cLPB group had unilateral sensory block, classified as grade 2 in $87.1 \%$ of patients $(n=74)$. In the epidural group, blockade was bilateral being classified as grade 2 in $75.3 \%$ of patients $(n=58)$.

Rescue analgesic dose ( $5 \mathrm{~mL}$ of $0.2 \%$ ropivacaine) was needed for $23.5 \%$ of patients $(n=20)$ of the cLPB group and for $22.1 \%$ of patients $(n=17)$ of the epidural group. The incidence of patients needing at least one rescue dose was not significantly different between groups. Rescue doses were primarily administered in the first postoperative day for $22.4 \%$ of cLPB group ( $n=19)$ and $22.1 \%$ of epidural group $(n=17)$, most cases needing just one dose $(15.3 \%$ of cLPB versus $18.2 \%$ epidural). The need for rescue doses has significantly decreased in both groups in the second $(2.4 \%$ cLPB versus $2.6 \%$ epidural) and third postoperative days (1.2\% cLPB versus $1.3 \%$ epidural) (Figure 3 ).

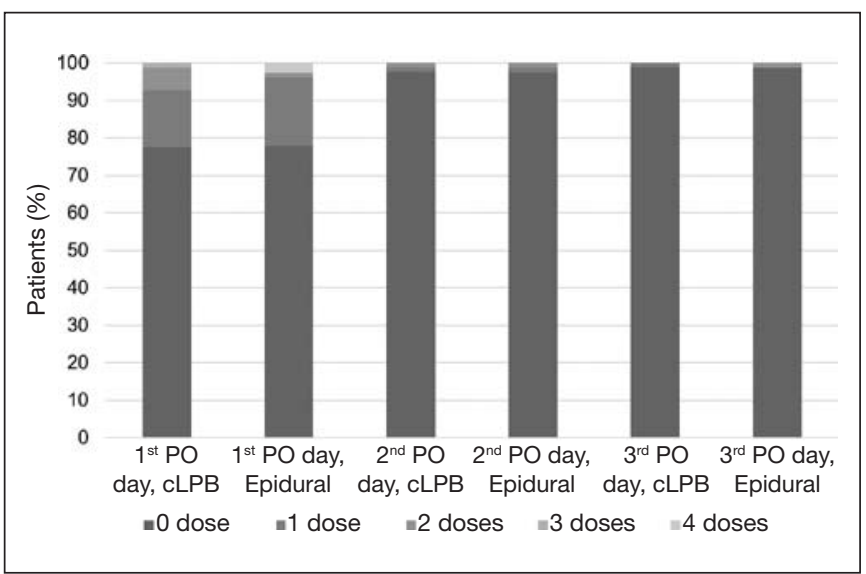

Figure 3. Comparison of the number of rescue doses during the three postoperative days for both groups

The incidence of complications for both groups is shown in table 2. cLPB group had a total number of complications significantly lower as compared to the epidural group ( $4.7 \%$ cLPB versus $23.4 \%$ epidural). However, the scarce incidence of each complication does not allow establishing statistically significant differences between groups. With regard to motor block degree, there has been blockade degree 1 in $1.2 \%$ of patients $(n=1)$ with cLPB analgesia and in $3.9 \%$ of patients $(\mathrm{n}=3)$ with epidural analgesia. Pruritus was reported only by the epidural group, with incidence of $9.1 \%(n=7)$. The incidence of nausea and vomiting was higher in the epidural group (3.5\% cLPB versus $10.4 \%$ epidural). There was one patient of each group in whom the catheter was exteriorized and in both cases APU discharge was determined for considering that patients no longer needed analgesic intervention.

Table 2. Comparison of complications for both groups

\begin{tabular}{lcccc}
\hline Groups & $\begin{array}{c}\text { Motor } \\
\text { block }\end{array}$ & $\begin{array}{c}\text { Nausea \& } \\
\text { vomiting }\end{array}$ & Pruritus & Total \\
\hline cLPB $(n=85)$ & $1(1.2 \%)$ & $3(3.5 \%)$ & 0 & $4(4.7 \%)$ \\
Epidural $(n=77)$ & $3(3.9 \%)$ & $8(10.4 \%)$ & $7(9.1 \%)$ & $18(23.4 \%)$ \\
Total $(n=162)$ & $4(2.5 \%)$ & $11(6.8 \%)$ & $7(4.3 \%)$ & $22(13.6 \%)$ \\
\hline CLPB = continuous lumbar plexus block.
\end{tabular}

Most patients were discharged in the third postoperative day, namely $68.2 \%$ of cLPB $(n=58)$ and $72.7 \%$ of epidural block patients $(\mathrm{n}=56)$. Among remaining patients, $20 \%$ of cLPB group $(n=17)$ and $22.1 \%$ of epidural group $(n=17)$ were discharged in the fourth postoperative day; $10.6 \%$ of cLPB $(n=9)$ and $5.2 \%$ of epidural $(n=4)$ were discharged in the fifth postoperative day; $1.2 \%$ of $\operatorname{cLPB}(\mathrm{n}=1)$ was discharged in the sixth postoperative day.

\section{DISCUSSION}

This study has shown that cLPB has provided analgesic efficacy equivalent to epidural block, with the advantage of presenting a better safety profile. Mean hospitalization time was also similar for both techniques.

This shows the clinical practice reality of the studied institution. However, it is necessary to take into account limitations inherent to a retrospective design, such as administration of different ropivacaine doses for the cLPB group $(0.2 \%$ ropivacaine) and the epidural group ( $0.1 \%$ ropivacaine), the association of fentanyl only in the epidural group and random load dose administered in the perioperative period for epidural analgesia. Another limitation of this study was the low incidence of complications, which does not allow determining the existence of statistically significant differences between groups.

As to the evaluation of analgesic efficacy, epidural and cLPB groups were not different in pain intensity or the incidence of rescue doses, but the incidence of complete sensory block was higher in the cLPB group. During the first postoperative day, cLPB group had $92.9 \%$ of patients with no pain or mild pain at rest, not differing from the epidural analgesia group with $93.5 \%$ of patients in the same conditions. With regard to pain at movement during the first postoperative day, most patients had no pain and from remaining patients most reported mild pain.

Rescue doses are primarily administered in the first postoperative day, stressing that a similar number of patients of both groups have not needed rescue analgesia $(77.6 \%$ cLPB versus $77.9 \%$ epidural). In both groups, POP at rest and at movement, as well as the need for rescue doses, have considerably decreased in the second and third postoperative days. The incidence of complete sensory block is lower in the epidural group, with the presence of bilateral block in case of epidural block and unilateral block for cLPB. Results also suggest that adopted analgesia regimens are adequate for the postoperative period of patients submitted to hip arthroplasty. Scarce literature data report that LPB provides excellent intra and postoperative analgesia, decreases opioid consumption, speeds recovery and has few adverse effects ${ }^{5,7,8}$.

Türker et al. ${ }^{8}$ have compared LPB and epidural analgesia and have not found statistically significant differences in pain intensity and postoperative rescue analgesia consumption. Ilfeld et al. ${ }^{9}$ have concluded that most patients submitted to THA under analgesia with cLPB by Patient Controlled Regional Analgesia could walk 30 meters and be discharged in the first postoperative day. However, these results also differ from other studies. Duarte et al. ${ }^{3}$ have reported that patient 
controlled epidural analgesia with $0.2 \%$ ropivacaine and $3 \mu \mathrm{g} /$ $\mathrm{mL}$ fentanyl promotes more effective pain relief at rest and during mobilization as compared to cLPB with $0.2 \%$ ropivacaine and that both techniques are equivalent for functional rehabilitation. The incidence of rescue analgesia for the cLPB group was $23.5 \%$, being much higher than $6.5 \%$ reported by Capdevilla et al. ${ }^{4}$. This difference is probably due to different perfusion techniques, since that study has used mechanical infusion pump, while the protocol of this study has used perfusion with elastomer with its inherent flow fluctuations $s^{4}$.

Few adverse effects were observed in our study, which is in line with other studies ${ }^{4}$. The cLPB group had lower incidence of complications as compared to the epidural group. The incidence of motor block and nausea and vomiting was lower in the cLPB group, although the difference was not statistically significant. The higher incidence of nausea and vomiting in the epidural group may be explained by the association of fentanyl in this group. No cLPB group patient has complained of pruritus, differently from $9.1 \%$ of patients with the epidural catheter who presented this complaint. Unfortunately, the low incidence of secondary effects and complications in the sample does not allow inferring the existence of significant differences between cLPB and epidural techniques. cLPB seldom has severe complications being known intoxication by local anesthetics following inadvertent intravascular injections, spinal administration, intraperitoneal puncture, subcapsular renal hematoma by renal perforation and retroperitoneal hematoma ${ }^{1,3,5}$.

Drug dispersion to the epidural space was considered by other authors as the most frequent LPB complication, with incidence of $5 \%$ 4,5,10. Chosen approach for the blockade has not influenced bilateral local anesthetic epidural diffusion, being most probable causes the injection of large volumes ${ }^{10}$ and the injection pressure, especially pressures above $20 \mathrm{psi}^{11}$. The lack of severe complications in our study may be associated to the safety provided by the dual guidance technique, which combines electric stimulation and ultrasound to confirm correct needle location ${ }^{12}$.

Although not recommended as routine in case of low analgesic efficacy, blood traces in the catheter or negative catheter aspiration, catheter position was confirmed in our study by means of X-rays with contrast injection. The best way to avoid intravascular injection is still aspiration previous to injection, negative test dose and fractioned and slow administration of drugs, although there might be false negative results ${ }^{10}$. LPB is a very deep block which should not be induced in patients with altered coagulation test or platelet dysfunction and it is recommended to be induced by experienced professionals ${ }^{1,3,5}$. In our institution, the same anticoagulation standards used for placement and removal of epidural catheters were used for cLPB.

There are no differences between cLPB and epidural groups with regard to hospitalization time. Most patients of both groups were discharged in the third postoperative day and almost all patients of the sample were discharged before the fourth postoperative day. Our results are different from stud- ies suggesting that cLPB speeds postoperative recovery ${ }^{8,13}$, suggesting that recovery times are similar for both groups. Reports of severe complications and familiarity with other techniques may explain the reluctance of anesthesiologists in choosing LPB. However, epidural analgesia has known secondary effects ${ }^{14}$. Our study confirms scarce studies results which conclude that CLPB may provide similar or better analgesia as compared to epidural block, with the advantages of decreasing the incidence of adverse effects ${ }^{8,13}$. The Prospect Group recommends cLPB for postoperative analgesia of THA in situations where general anesthesia is the choice ${ }^{15}$. We hope that this study contributes to the demystification of postoperative analgesia with cLPB and calls the attention of anesthesiologists to the advantages of this technique.

\section{CONCLUSION}

Our study suggests that cLPB is a safer technique with analgesic efficacy equivalent to epidural block for hip arthroplasty. Based on our results and on existing literature, it seems that cLPB could be a valid alternative to epidural block. In spite of reflecting the clinical practice of our institution and of the inherent limitations of the method, we believe that our results might condition a change in hip arthroplasty postoperative analgesia paradigm, contributing to a safer analgesic practice. We stress the need for multicenter, prospective and randomized studies, with larger samples to determine the role of cLPB in hip arthroplasty postoperative analgesia, as well as its hemodynamic effects.

\section{ACKNOWLEDGEMENTS}

The authors acknowledge the cooperation of the APU nursing group of the Centro Hospitalar Alto Ave, Guimaráes, Portugal.

\section{REFERENCES}

1. YaDeau JT, Tedore T, Goytizolo EA, Kim DH, Green DS, Westrick A. et al. Lumbar plexus blockade reduces pain after hip arthroscopy: a prospective randomized controlled trial. Anesth Analg. 2012;115(4):968-72.

2. Duarte LT, Paes FC, Fernandes Mdo C, Saraiva RA. Posterior lumbar plexus block in postoperative analgesia for total hip arthroplasty: a comparative study between $0.5 \%$ bupivacaine with epinephrine and $0.5 \%$ ropivacaine. Rev Bras Anestesiol. 2009;59(3):273-85. English, Portuguese.

3. Duarte LT, Beraldo PS, Saraiva RA. Effects of epidural analgesia and continuous lumbar plexus block on functional rehabilitation after total hip arthroplasty. Rev Bras Anestesiol. 2009;59(5):531-44. Portuguese.

4. Capdevila X, Macaire P, Dadure C, Choquet O, Biboulet P, Ryckwaert Y, et al. Continuous psoas compartment block for postoperative analgesia after total hip arthroplasty: new landmarks, technical guidelines, and clinical evaluation. Anesth Analg. 2002;94(6):1606-13

5. Touray ST, de Leeuw MA, Zuurmond WW, Perez RS. Psoas compartment block for lower extremity surgery: a meta-analysis. Br J Anaesth. 2008;101(6):750-60.

6. Karmakar MK, Ho AM, Li X, Kwok WH, Tsang K, Ngan Kee WD. Ultrasound-guided lumbar plexus block through acoustic window of the lumbar ultrasound trident. Br J Anaesth. 2008;100(4):533-7.

7. Freitas HF, Flores F, Lima LC, Couceiro TC, Neves M, Lira C. et al. Avaliação da analgesia pós-operatória em artroplastias de quadril com morfina por via subaracnoidea associada ao bloqueio " 3 em 1": estudo aleatório e encoberto. Rev Dor. 2012;13(2):137-40.

8. Türker G, Uçkunkaya N, Yavascaoglu B, Yilmazlar A, Ozçelik S. Comparison of the catheter-technique psoas compartment block and the peridural block for analgesia in partial hip replacement surgery. Acta Anaesthesiol Scand. 2003;47(1):30-6.

9. Ilfeld BM, Gearen PF, Enneking FK, Berry LF, Spadoni EH, George SZ, et al. Total hip arthroplasty as an overnight-stay procedure using an ambulatory continuous pso- 
as compartment nerve block: a prospective feasibility study. Reg Anesth Pain Med. 2006;31(2):113-8.

10. Mannion S. Psoas compartment block. Continuing education in anaesthesia. Crit Care Pain. 2007;7(5):162-6.

11. Gadsden JC, Lindenmuth DM, Hadzic A, Xu D, Somasundarum L, Flisinski KA. Lumbar plexus block using high-pressure injections leads to contralateral and epidural spread. Anesthesiology. 2008;109(4):683-8.

12. Carvalho I, Costa G, Lages N, Correia C. Cirurgia da anca e bloqueio do plexo lombar. Rev Soc Port Anestesiol. 2015;24(1):6-11.
13. Biboulet P, Morau D, Aubas P, Bringuier-Branchereau S, Capdevila X. Postoperative analgesia after total-hip arthroplasty: comparison of intravenous patient-controlled analgesia with morphine and single injection of femoral nerve or psoas compartment block: a prospective, randomized, double-blind study. Reg Anesth Pain Med, 2004;29(2):102-9.

14. de Leeuw MA, Zuurmond WW, Perez RS. The psoas compartment block for hip surgery: the past, present, and future. Anesthesiol Res Pract. 2011;2011:159541.

15. postoppain.org. PROSPECT working group - procedure specific postoperative pain management. Disponível em: http://www.postoppain.org/frameset.htm. 